\title{
GIVEN AND NEW INFORMATION IN BARACK OBAMA'S REMARKS: A SYNTACTIC FORM ANALYSIS
}

\author{
Herdiana $^{1}$, Didin Nuruddin Hidayat ${ }^{1}$, Alek ${ }^{1}$, \& Nida Husna ${ }^{1}$ \\ ${ }^{1}$ Department of English Education, Faculty of Educational Sciences, UIN Syarif Hidayatullah \\ Jakarta \\ Corresponding Author Email: didin.nuruddin@uinjkt.ac.id
}

\begin{tabular}{|c|c|}
\hline Article Info & Abstract \\
\hline $\begin{array}{l}\text { Article History } \\
\text { Received: August } 2020 \\
\text { Revised: September } 2020 \\
\text { Published: October } 2020\end{array}$ & $\begin{array}{l}\text { This study seeks to figure out how certain new and given information as } \\
\text { information structure of syntactic forms are revealed in Barack Obama's remarks } \\
\text { in Jakarta. The study is focused on the beginning parts of Obama's remarks, as } \\
\text { in that he recalled his childhood memories of staying in Jakarta, Indonesia, for }\end{array}$ \\
\hline $\begin{array}{l}\text { Keywords } \\
\text { Discourse Analysis; } \\
\text { Information Structure; } \\
\text { Speech; } \\
\text { Syntactic Form; }\end{array}$ & $\begin{array}{l}\text { four years. In order to investigate the information structures, we collected the } \\
\text { data from digital documents (scripts and videos) of the remark; then, we analyzed } \\
\text { the syntactic forms of article "a" (indefinite) and "the" (definite) and also the } \\
\text { rheme and theme of the script and the video of the remarks using close textual } \\
\text { analysis. The results indicate that the uses of these articles construct certain } \\
\text { messages whose tones are either distancing, getting close, or neutralizing the } \\
\text { speaker against the audience. Furthermore, the information contained in } \\
\text { Obama's speech reflected the context-awareness of the speaker and also the } \\
\text { audience. The speech could also open up further study on (political) critical } \\
\text { discourse analysis, as it was delivered in the political contexts between Indonesia } \\
\text { and the USA. }\end{array}$ \\
\hline
\end{tabular}

How to cite: Herdiana, Hidayat, D. N., Alek, \& Husna, N. (2020). Given and new information in barack obama's remarks: a syntactic form analysis. JOLLT Journal of Languages and Language Teaching. 8(4), 458-464. DOI: https:/doi.org/10.33394/jollt.v\%vi\%i.2827

\section{INTRODUCTION}

Through speeches, a leader conveys ideas, even certain discourses. Each leader has a unique speech style that is different from the others. This is because each string of words spoken when making an indirect speech is a reflection of that person's personality. Furthermore, from speech it can be revealed certain information structures, especially if some concerns on linguistics are emphasized.

One of the public figures respected for their speeches is the former President of the United States, Barack Obama. In November 2010, he made his first official visit to Indonesia, a country where he spent his four-year childhood back then 1968 until 1971. In this visit, Obama was expected by the Indonesian people to address some strategic areas between Indonesia and the United States. In November 2010, in front of officially invited Indonesian people, the president made a historical remark at Universitas Indonesia, Jakarta.

The remarks that the president delivered intersected with various strategic issues Indonesia and the US were facing, such as culture, politics, economy, history, and the likes. However, from the various landscapes, Obama highlighted, as Indonesian citizens, a curiosity is encountered on how Obama recalled his memories of childhood in Indonesia. The president conveyed his enactment about Indonesia, especially Jakarta, in the opening parts of the speech. Therefore, it is relevantly explorative to find out how he constructed his recalling about Indonesia through the sentences, phrases, words, even attitudes, and other linguistic units in the remarks. Bayram (2010) notes that attitudes to language can be linked to social and cultural identity, to social status, and the notions of prestige and solidarity, and those attitudes to 
language and its varieties can be influenced by different factors related to the users of that specific language. This can be constructed by focusing on the information structures (given and new information) by analyzing the syntactic forms, with the focus on how certain articles "a" and "the" and rhyme and theme are devised.

Furthermore, discourse is not simply an entity we can define independently: we can only arrive at an understanding of it by analysing sets of relations. It can be said what it is in particular that discourse brings into the complex relations which constitute social life: meaning and making meaning (Fairclough, 2013). Meaning making is a cooperative enterprise (linguistic or otherwise) that always takes place in a large set of contexts (ranging from immediate to background), and that occurs with varying degrees of success. People who can successfully participate in this kind of meaning-making can be said to belong to the same culture (Kovevses, 2010).

The series of investigation of information structure in utterances was established by linguists of the Prague School before the Second World War. The linguists proposed what they considered 'the communicative dynamism' of the components building up a sentence in the construction of 'functional sentence perspective' (Vachek, 1966; Hladký, 2003). In particular, the Prague School treat information as it consists of two classifications, namely new information, which is information that the addressor considers not known to the addressee; and given information that the addressor concludes is recognizable to the addressee (either for it is factually in existence in the setting or due to being having been presented in the discourse).

Halliday and Hasan (1976) later were in line with the Prague School in proposing that one of the uses of intonation in English is to sign up which information the utterer is considering new and which information the utterer is considering given. Apparently, nowadays, the discourse of 'given' and 'new' information to the stretch of syntactic structures that are attached to realize the categories of information has become one of the topics of interest in the linguistic area (Kashiwadate, Yasuda, Fujita, Kita, \& Kobayashi, 2020; Szaszák \& Beke, 2012; Chen \& Zechner, 2011).

Halliday and Hasan (1976) proposed that the speaker tries to signify the essence of the utterance (the foundational unit in his grammatical analysis). At certain points, what Halliday considers the 'ideational' essence of a clause might be benchmarked with what others have proposed the 'prepositional' content of a modest utterance. The content of this clause is organized by the utterer in a syntactic structure of the clause, in which the utterer selects among the selections of theme in existence to him or her. Meanwhile, in spoken communication, a content of a clause is organized through one set or more units of information that are realized phonologically by intonation.

Halliday and Hasan (1976) indicate that the speaker is conditioned to break down his or her speech into units of information. He or she has to convey the message in packages of serials. Nevertheless, he or she is free to set up how he or she expects to wrap up the information. He has the freedom to settle down where every information unit starts and stops, and how it is organized internally'. Prior to that, as the utterer has decided to inform his hearer that, for example, in "John has gone to the garden with Mary", the speaker may attach this information into one unit of utterance. Halliday proposes that the speaker will put given information in order before new information.

Here we shall discover the use of two articles (A) and (THE). (A) represent our primary perception and denotes individual as unknown; (THE) respect our secondary perception and denotes individuals as known.

An example:

a. I see an object pass by, which never saw till then, what do I say?

"There goes A Beggar, with A long Beard."

b. Then Man departs, and returns a week after 
"There goes the Beggar with THE long Beard."

The article only is changed. (Harris, 1751: 2015-16) ("Zellig Harris: Language and Information," n.d.)

The discussion where the examples are extracted are dealt with syntactic realization. In constructing sequence, sentence, in which some units are in the second sentence, is deemed to be in some sense 'given'. In the example, we find two predominant forms of utterance applied to signify an entity labelled as given, namely pronoun and definite NPs. These forms are often treated in the linguistics discourse as thought they were in free variation.

An example: - "They were stolen by a customer"

- "The jewels were stolen by a customer"

In some cases, repetition makes the discourse appear to be like a dazzling language of the first child's reader. If a dazzling language is noticed, this is presumably because normally, in genres other than children first's reader, and the speaker does not reiterate contextually much 'given' information. Moreover, in the case of Barack Obama's remarks, the uses of pronouns in political speeches follow approximately the same pattern. However, it is what these pronouns are intended to convey in terms of whom or what is included in the group that demonstrates the inclusivity of the president (Stobbs, 2012). This proposition can be made sense by focusing on the information structures (given and new information) by analyzing the syntactic forms, with the focus on how certain articles "a" and "the" and rhyme and theme are devised. Regarding this notion, this study is focused on the beginning parts of Obama's remarks, as in that he recalled his childhood memories of staying in Jakarta, Indonesia, for four years. The study seeks to scrutinize how certain new and given information as information structure of syntactic forms are revealed in Barack Obama's remarks in Jakarta.

\section{RESEARCH METHOD}

Topics are typically presumable information, and they are the starting point of the sentence. Focused nominals, on the other hand, are the end goal of the sentence, the information which the speaker intends to attach to the discourse. Furthermore, the topic tends to resume the starting point of a sentence and focus toward the ultimate point. Topics are closely correlated with the given or old information, which is currently in the speaker's awareness, while focused constituents are new information, just being extracted into the discourse. The concept of given information is relatively equivalent to presupposed, but new information need not (although it usually does) be in line with only the focused constituent (Lambrecht, 1996).

\section{Research Design}

The design of this study is close textual analysis (Ruark \& Fielding-Miller, 2016). Close textual analysis here means that the researchers closely read the relationship among certain linguistic units of discourse, with the focus on syntactic forms of definite and indefinite articles, rhymes, and themes. This is done so to discover what makes a particular text function for both the speaker and the hearer(s). The researchers analyze how Obama uses the article "a" and "the,", rhyme and theme in his address that he may intend to deliver (certain) messages to the audience. For example, Obama used his particular theme of "us" and "we".

\section{Instruments}

Instruments of research are tools built up by researchers for reaching the projected purposes when conducting research. Practically, the instruments are designed devices to assist in collecting data to be analyzed. Miles and Huberman (2002) describe research instrumentation as specific means which is focused on gathering information, and it can be closely or openly structured. In this study, the author applies a close textual analysis over the digital and printed 
documents of Barack Obama's speech at Universitas Indonesia Campus delivered in November 2010.

\section{Data Analysis}

The data were collected from digital documents (scripts and videos) of the remark. Then the syntactic forms of article "a" (indefinite) and "the" (definite) and also the rheme and theme of the script and the video of the remarks were analyzed using close textual analysis. The authors conducted close textual analysis on the object of this study. The close textual analysis resumed as the following cycle: data collection, data display, data reduction (based on the objectives of this study), and the conclusion.

\section{RESEARCH FINDINGS AND DISCUSSION Research Findings}

The remarks that President Obama made was around one-hour long. As mentioned before, this paper is focused on analyzing the beginning parts of the remarks, as in that it catches the authors attention on how Obama recalled his memories about Indonesia, especially Jakarta, for reconditioning his address and also for fixing his diplomatic purposes, which is in this case political.

Before going further to the main part of his speech, President Obama recalled his memories about Indonesia, particularly Jakarta. In his recalling memories, it is noticed how he narrated some points in which he devised the article "a" and "the". The ways he devised these indefinite and definite articles could lead to some propositions, as the articles indicate certain information, either new or old ones.

The list ${ }^{1}$ of Obama's sentences that contain the articles is as follows:

a. "I first came to this country when my mother married an Indonesian named Lolo Sutoro."

b. "As a young boy, I was coming to a different world."

c. "But the people of Indonesia quickly made me feel at home."

d. "The city was filled with buildings that were no more than a few stories tall."

e. "The Hotel Indonesia was one of the few high rises, ...."

f. "And you didn't have all the big highways that you have today."

g. "And we lived in a small house."

h. "We had a mango tree out front."

i. " $\quad$ And I learned to love Indonesia while flying kites and running along the paddy fields and catching dragonflies, buying satay and bakso (meatballs) from the street vendors."

j. "I still remember the call of the vendors. Satay!"

k. "But most of all, I remember the people -- the old men and women who welcomed us with smiles; the children who made a foreign child feel like a neighbor and a friend; and the teachers who helped me learn about this country."

1. "So much has changed in the four decades since I boarded a plane to move back to Hawaii."

m. "The Jakarta that I once knew has grown into a teeming city of nearly 10 million, with skyscrapers that dwarf the Hotel Indonesia..."

n. "When my stepfather was a boy, he watched his own father and older brother leave home to fight and die in the struggle for Indonesian independence."

\footnotetext{
${ }^{1}$ See Appendix 1 for the details (full script)
} 
o. "And I'm happy to be here on Heroes Day to honor the memory of so many Indonesians who have sacrificed on behalf of this great country."

p. "In the years since then, Indonesia has charted its own course through an extraordinary democratic transformation -- from the rule of an iron fist to the rule of the people."

q. "In recent years, the world has watched with hope and admiration as Indonesians embraced the peaceful transfer of power and the direct election of leaders."

\section{Discussion}

It is intriguing to see the context of Obama's remark in Jakarta. In a study, Morales-Lopez (2019) highlights that in linguistics, we should talk about the environment of the speakers and the environment of words inside the linguistic system itself (that we commonly name context). The information contained in Obama's speech reflected the context-awareness of the speaker and also the audience.

In sentence (a), the speaker puts a distance with the audience. He started the discourse (about his initial 'engagement' with Indonesia) in a 'neutral' but focused tone. He indicated that it was the first time he introduced that person (Lolo Soetoro) in the speech. Here it also got a signal that there were most likely Indonesians whose names were Lolo Soetoro, not just 'this' Lolo Soetoro. Hence, in this case, Obama was trying to deliver new information to the audience. It also indicated that he was positioning himself as a 'neutral' storyteller. There are other utterances most likely having the same proposition as "my mother married an Indonesian named Lolo Sutoro" but more engaged, for example: "my mother married my late Indonesian father in law Lolo Sutoro". The nuance of distancing in the phrase "and Indonesian named Lolo Sutoro" appears to be apparent.

The same nuance as (a) also appeared in sentence (b). He was capturing a portrait of a young boy, who was, in this linguistic unit, the third person: "a young boy", who was himself. Besides the storyteller 'style', it is also intriguing to notice how the speaker used the phrase "a different world" (to refer to Indonesia, specifically Jakarta). Jakarta as a geographical entity was not mentioned as the way it was said and written; instead, it was 'devised' rhetorically to address diplomatic impression in a 'stylistic' manner, which was, in this case, could not be separated from the role of article "a" as a linguistic unit.

When the speaker said, "The people...." (c)He referred to a group of persons. But which group? Contextually, the ones who welcomed him nicely that made him say, "... made me feel at home". The rheme seen here is in a positive proposition. Nevertheless, as it has been the main focus, the role of the article "the" signifies how the tone of an utterance makes sense, both for the speaker and the hearer. Sentence (c) will logically fail to address the main idea of the speaker if "the" is omitted.

In short, Obama was trying to 'get close' to the audience. Even he used his gestures (pointing out his hands at the audience with fingers) saying, "(Applause) -- hey, some folks from Menteng Dalam right here. (Applause)". He started the remarks with the "naturally' neutral signification, then continued to the point where he 'touched' the line to get closer to the audience.

Moreover, to underline the significance of rheme, utterances (e) and (f) offer linguistic units to ponder. In these two sentences, Obama showed a proposition that all audiences were at the same understanding with the information he delivered (the Hotel Indonesia and the big highway). The articles "the" in both sentences help to construct linguistical, social, even political messages in the discourse the speaker was addressing. After all, the tone of these sentences, as mostly found in the rest of the remarks, was positive (Batluk, 2011). This proposition also intersects with what Capone (2010) indicates that Obama takes the politician's role as representative (of the people) seriously and expresses the voices he wants to represent. It is to support his ideas about politics, in respect to which he presents himself as the animator, 
while giving ordinary people the role of principals. This leads to a notion that Lingua Franca English, or any other languages, cannot be understood "outside the realm of practice"; language is not so much located in the mind of the speaker as it is a social process constantly reconstructed in sensitivity to environmental factors (Pennycook, 2010).

\section{CONCLUSION}

From how and to what extent Obama devised definite and indefinite articles, it could be figured out certain information indicating he was sure that Indonesians (as the audience) realized and did not realize contextually. Furthermore, in doing so, it is noticeable that at certain points, he was to get close to the audience, and then he also tried to make some 'distance' with them.

Another point to consider is that the remarks of Obama does not merely intend to bring communicative or social purposes regarding the bilateral relationship between Indonesia and the USA. However, more than that, it conveys political messages and issues, particularly between the USA and Indonesia, generally in the sense of global affairs. Regarding this point, Kezemian and Hashemi (2014) asserted that upon inquiring into these speeches, one could find both syntactic and lexical parallels. There is the influence of reiteration of the same words or clauses or even certain connections between words, mostly associated to the same parts of speech, such as verbs or nouns. It is also worth noting that there is a large number of parallel structures in these texts in which not only they call the audience attention and underscore the topic but also they add balance and rhythm as well as clarify and beautify the sentences.

The speech can also be analyzed by the critical discourse analysis as it relates to how power was being maintained by Obama. Therefore, this article is expected to contribute more to further study of discourse analysis or even more than that, any study related to the power relation between Indonesia and the United States of America (USA). This corresponds to what Fairclough (2003) points out that textual analysis approach to the linguistic analysis of text is always oriented to the social character of texts. However, Lin (2003) warns that one key distinction between CDA and discourse studies lies in CDA's consistent focus on language as social practice and particularly on the social and political context of language use. CDA is not interested in investigating language as a static linguistic entity but in studying social and discursive processes and their consequences.

\section{REFERENCES}

Batluk, L. (2011). Rhythm and Rhetoric: A Linguistic Analysis of Barack Obama Inaugural Address. Retrieved from http://urn.kb.se/resolve?urn=urn:nbn:se:hh:diva-15601.

Bayram, F. (2010). Ideology and Political Discourse: A Critical Discourse Analysis Of Erdogan's Political Speech. Annual Review of Education, Communication \& Language Sciences, 7.

Capone, A. (2010). Barack Obama's South Carolina speech. Journal of Pragmatics, 42(11), 2964-2977.

Chen, M., \& Zechner, K. (2011). Computing and evaluating syntactic complexity features for automated scoring of spontaneous non-native speech. Proceedings of the 49th annual meeting of the Association for Computational Linguistics: Human Language Technologies (pp. 722-731). Portland: Association for Computational Linguistics.

Fairclough, N. (2013). Critical Discourse Analysis: The critical study of language. Routledge. Fairclough, N. (2003). Analysing discourse: Textual analysis for social research. Psychology Press.

Halliday, M. A. K., \& Hasan, R. (1976). Cohesion in English. Longman. 
Harris, Z. (2018). Language and Information. Retrieved December 18, 2019, from http://zelligharris.org/

Hladký, J. (2003). Language and Function: To the Memory of Jan Firbas. John Benjamins Publishing.

Huberman, M., \& Miles, M. B. (2002). The qualitative researcher's companion. Sage.

Kashiwadate, K., Yasuda, T., Fujita, K., Kita, S., \& Kobayashi, H. (2020). Syntactic Structure Influences Speech-Gesture Synchronization. Letters on Evolutionary Behavioral Science, 11(1), 10-14.

Kazemian, B., \& Hashemi, S. (2014). Critical discourse analysis of Barack Obama's 2012 speeches: Views from systemic functional linguistics and rhetoric. Theory and Practice in Language Studies (TPLS), 4(6), 1178-1187.

Kövecses, Z. (2010). Metaphor, language, and culture. DELTA: Documentação de Estudos em Lingüística Teórica e Aplicada, 26, 739-757.

Lambrecht, K. (1996). Information structure and sentence form: Topic, focus, and the mental representations of discourse referents (Vol. 71). Cambridge University Press.

Lin, A. (2013). Critical Discourse Analysis: Overview. The Encyclopedia of Applied Linguistics. Oxford: Blackwell.

Morales-López, E. (2019). Discourse Analysis: The Constructivist Perspective and Transdisciplinarity. In Complexity Applications in Language and Communication Sciences (pp. 187-205). Springer, Cham.

Pennycook, A. (2010). Language as a local practice. Routledge.

Ruark, A., \& Fielding-Miller, R. (2016). Using qualitative methods to validate and contextualize quantitative findings: A case study of research on sexual behavior and gender-based violence among young Swazi women. In Global Health Science and Practice (pp. 373-383). https://doi.org/10.9745/GHSP-D-16-00062

Stobbs, G. J. (2012). Critical Discourse Analysis of Barack Obama's 1st Inaugural Speech. Xi'an Jiaotong-Liverpool University.

Szaszák, G., \& Beke, A. (2012). Exploiting prosody for automatic syntactic phrase boundary detection in speech. Journal of Language Modelling, 142-172.

Vachek, J. (1966). The Linguistic School of Prague 1966 Edition. Indiana University.

\section{APPENDICES}

Appendix 1: The speech (script)

Links: https://obamawhitehouse.archives.gov/the-press-office/2010/11/10/remarks-president$\underline{\text { university-indonesia-jakarta-indonesia }}$

Appendix 2: The video of the speech

Links: https://www.youtube.com/watch?v=9ycm9EBH9QM (1 of 4)

https://www.youtube.com/watch?v=zl vCj2t19k (2 of 4)

https://www.youtube.com/watch?v=FIGrM3enIUA (3 of 4)

https://www.youtube.com/watch?v=SB385EARyW4 (4 of 4) 